\title{
Monitoring of Dry Cutting and Applications of Cutting Fluid for Ball End Milling
}

\author{
Somkiat Tangjitsitcharoen ${ }^{\dagger}$ \\ Department of Industrial Engineering \\ Chulalongkorn University, Phayathai Road, Pathumwan Bangkok 10330, THAILAND \\ Tel: +66-02-218-6853, E-mail: Somkiat.T@eng.chula.ac.th \\ Channarong Rungruang \\ Department of Industrial Engineering \\ Chulalongkorn University, Phayathai Road, Pathumwan Bangkok 10330, THAILAND \\ Tel: +66-02-218-6853, E-mail: chan_pe20@yahoo.co.th \\ Duangta Laiaddee \\ Department of Industrial Engineering \\ Chulalongkorn University, Phayathai Road, Pathumwan Bangkok 10330, THAILAND \\ Tel: +66-02-218-6853, E-mail: duangta.1@hotmail.com
}

Received, March 22, 2010; Revised, July 25, 2010; Accepted, July 22, 2010

\begin{abstract}
For economical and environmental reasons, the aim of this research is hence to monitor the cutting conditions with the dry cutting, the wet cutting, and the mist cutting to obtain the proper cutting condition for the plain carbon steel with the ball end milling based on the consideration of the surface roughness of the machined parts, the life of the cutting tools, the use of the cutting fluids, the density of the particles of cutting fluids dispersed in the working area, and the cost of cutting. The experimentally obtained results of the relation between tool wear and surface roughness, the relation between tool wear and cutting force, and the relation between cutting force and surface roughness are correspondent with the same trend. The phenomena of surface roughness and tool wear can be explained by the in-process cutting forces. The models of the tool wear with the cutting conditions and the cutting times are proposed to estimate the tool cost for the different cooling strategies based on the experimental data using the multiple regression technique. The cutting cost is calculated from the costs of cutting tool and cutting fluid. The mist cutting gives the lowest cutting cost as compared to others. The experimentally obtained proper cutting condition is determined based on the experimental results referring to the criteria.
\end{abstract}

Keywords: Ball End Milling, Dry Cutting, Wet Cutting, Mist Cutting, Cutting Force, Tool Life

\section{INTRODUCTION}

Nowadays, the steel family such as the plain carbon steel is most popularly used for the mechanical parts, mainly automotive parts. The ball-end milling process is one of the important cutting processes, which is used to cut those materials in order to obtain the shape of the parts as required. However, the tool wear is still the main problems in the ball-end milling process because it deteriorates not only the machined surfaces but also geometry and accuracy as well as causing the low productivity due to the interruptions of the machining op- erations to change the new cutting tools.

In order to reduce $\mathrm{CO}_{2}$ emissions and waste in cutting processes, there has been a continuing worldwide trend to minimize or eliminate the use of cutting fluids (Diniz and Micaroni, 2002). This trend leads to the practice of minimum quantity lubrication (MQL) with major benefits such as reducing of machining operations and the disposal of cutting fluids (Sutherland et al., 2000; Kishawy et al., 2005; Thepsonthi et al., 2009).

Extensive research efforts have been devoted so far to investigate the effects of the cutting fluids and develop the applications of the MQL (Ii et al., 2000; Gun-

$\uparrow$ : Corresponding Author 
ter and Sutherland, 1999; Cakir et al., 2004; Weinert et al., 2004; Dhar et al., 2006). However, the effectiveness of the MQL depends on a number of factors, such as the type of machining operations, the cutting tools, the workpiece materials, the cutting conditions, and the cutting fluids. It is therefore desirable to know the effects of the different applications of the MQL under any cutting conditions during the cutting process in order to improve the stability of cutting (Rahman et al., 2002; Varadarajan et al., 2002).

It is already known that the cutting force can be used to examine and analyze the surface roughness, the tool wear and the cutting temperature (Somkiat, 2009). The in-process monitoring of cutting forces is hence proposed to investigate the cutting performance of the dry cutting, the wet cutting, and the mist cutting.

Hence, the aim of this research is to monitor the cutting conditions with the dry cutting, the wet cutting, and the mist cutting to obtain the proper cutting condition for the plain carbon steel with the ball end milling based on the consideration of the surface roughness of the machined parts, the life of the cutting tools, the use of the cutting fluids, the density of the particles of cutting fluids dispersed in the working area, and the cost of cutting.

\section{IN-PROCESS MONITORING OF BALL- END MILLING PROCESS}

The in-process monitoring of ball-end milling process is utilized to examine and analyze the cutting conditions with the various cooling strategies, which are the dry cutting, the wet cutting and the mist cutting. The inprocess cutting forces and particles of cutting fluid are monitored during the machining with ball end milling.

The dynamometer is employed and installed on the table of 5-axis CNC machining center in order to measure the in-process cutting force. The in-process cutting forces obtained are analyzed and interpreted for the surface roughness and the tool wear under various cutting conditions.

Due to the environmentally friendly process without the harmful effects and environmental hazards, the particles of cutting fluids dispersed during the cutting is continually monitored in order to check the applications of cutting fluid by utilizing the aerodynamic particle sizer spectormeter. The smallest size of the particles of cutting fluids is $0.5 \mu \mathrm{m}$, which can be measured.

\subsection{Relation of Tool Wear, Cutting Force, and Surface Roughness}

The applications of cutting fluid and the dry cutting may affect the tool wear rate and the cutting force. The cutting force is expected to be low while the tool wear rate is low. The surface roughness should be low when the tool wear is small. As the tool wear progresses, the cutting force is also increased mainly due to the increase in the force at the tool flank. Consequently the quality of surface roughness is poor.

Hence, the good surface roughness is expected to be obtained when the tool wear is small and the less cutting force happens and the cutting temperature is suitable. The cutting forces are low when the work materials become softer because of the suitably high cutting temperature.

On the other hand, the poor surface roughness is expected to be obtained when the tool wear is large and the high cutting force occurs, and the cutting temperature is unsuitable. The cutting forces are high when the work materials are still hard because of the unsuitably low cutting temperature.

\subsection{Relation of Cutting Condition, Tool Wear, and Surface Roughness}

The different cutting conditions applied with and without cutting fluid affect the cutting temperature during the in-process cutting. In case of the ball-end milling operation, the spindle speed is generally adopted as the major cutting condition to be monitored, as it is directly related to the tool wear and the cutting temperature. A selected spindle speed may cause the suitably in-process cutting temperature, and hence the work material becomes soft and easy to cut. Consequently the quality of surface roughness is good. It is expected that the tool wear rate is low and the small cutting force happens.

However, the high spindle speed may cause the highly in-process cutting temperature, and hence the rate of tool wear is high. The cutting force becomes large, as a result of the poor quality of surface roughness. It is expected that the increase in spindle speed causes the higher cutting temperature in the cut.

\section{EXPERIMENTAL EQUIPMENT AND CUTTING CONDITIONS}

In this research, the cutting experiments are carried out with three different cooling strategies, which are the dry cutting, the wet cutting, and the mist cutting in order to obtain the proper cutting condition. The cutting tests are performed by using the coated carbide ball end mills (TiAlN) and the tool diameters of 6 and $8 \mathrm{~mm}$ with two cutting edges, $30^{\circ}$ helix angle. However, the tool diameter of $8 \mathrm{~mm}$ will be investigated with the dry cutting only in this research. The cutting experiments of the tool diameter $8 \mathrm{~mm}$ with the wet and mist cutting will be monitored and discussed in the next research for more information.

The 5-axis machining center of Mazak Variaxis 500 is employed for the cutting tests. The workpiece material is plain carbon steel (S50C) with the size of $64 \mathrm{~mm}$ 
x $64 \mathrm{~mm}$ x $45 \mathrm{~mm}$. The major cutting conditions are shown in Table 1 . The values of cutting parameters are selected from the recommended values in the cutting tool manual (7-Leaders 2007/2008).

A Castrol clearedge EP 690 is used for the cutting fluid of the wet cutting and mist cutting with a dilution of $6 \%$. It is free from phenol and nitrite, suitable for metal cutting. The coolant is simultaneously applied at the rate of $16 \mathrm{l} / \mathrm{min}$ for the wet cutting and $90 \mathrm{ml} / \mathrm{min}$ in the mist cutting with the air pressure of $0.5 \mathrm{MPa}$. The dry cutting is performed without any air blow or internal cooling system. The limited flank wear (VB) is chosen here to be $0.2 \mathrm{~mm}$. The digital microscope of Keyence (model: VHX 600) is utilized to measure the flank wear of the cutting tool of the coated carbide ball end mill.

Table 1. Major cutting condition.

\begin{tabular}{|c|c|c|c|}
\hline Cutting Condition & $\begin{array}{c}\text { Dry Cutting } \\
\text { (D) }\end{array}$ & $\begin{array}{c}\text { Wet Cutting } \\
\text { (W) }\end{array}$ & $\begin{array}{c}\text { Mist Cutting } \\
\text { (M) }\end{array}$ \\
\hline \hline Spindle Speed, $v$ & 8,000 & 8,000 & 8,000 \\
(rpm) & 10,000 & 10,000 & 10,000 \\
12,000 & 12,000 & 12,000 \\
\hline Feed Rate, $f$ & 0.01 & 0.01 & 0.01 \\
(mm/tooth) & 0.03 & 0.03 & 0.03 \\
\hline Depth of Cut, $D$ & 0.3 & 0.3 & 0.3 \\
(mm) & 0.5 & 0.5 & 0.5 \\
\hline Width of Cut, $(\mathrm{mm})$ & 1.2 & 1.2 & 1.2 \\
\hline Cutting Tool & Coated carbide ball end mill (TiAlN) \\
\hline Tool Diameter (mm) & 6,8 & 6 & 6 \\
\hline \multicolumn{4}{|r}{} \\
\hline
\end{tabular}

The machined surface roughness is measured by using a surface roughness tester (TSK surfcom 1400D2). The arithmetic mean deviation of surface roughness $\mathrm{Ra}(\mu \mathrm{m})$ with a sampling length $\mathrm{lr}=2.5 \mathrm{~mm}$ (evaluation length $\ln =12.5 \mathrm{~mm}$ ) is applied as a surface finish evaluation criterion. The Ra, which is less than $5 \mu \mathrm{m}$, will be considered for the proper cutting condition.

A quartz three component tool dynamometer (Kistler 9257B) has been installed onto the table of the 5-axis $\mathrm{CNC}$ machining center as shown in Figure 1. The feed direction of the ball end mill is shown in Figure 2.

The dynamometer is used to measure the in-process cutting force. In general, the use of the dynamometer as a tool in ball end milling to monitor the dynamic cutting forces, it is hence necessary to eliminate noise signals from other sources by using the low-pass filter in the experiments. The resonant frequency of the dynamometer is about $3.5 \mathrm{kHz}$. However, it is proven by the modal test that the natural frequency of it included with the jig and the workpiece on the table of the 5-axis CNC machining center is $730 \mathrm{~Hz}$.

The sampling rate is selected at $1 \mathrm{kHz}$. The detected cutting force signals are amplified and low-pass filtered in order to avoid the natural frequency of the system or the chatter frequency with the cut-off frequency of 500 $\mathrm{Hz}$ prior to digitization and calculation within PC. Hence, the cutting forces obtained from the cutting experiments and the maximum spindle speed of $12,000 \mathrm{rpm}$ are well detected by the dynamometer. The cutting force, the surface roughness, and the flank wear are measured every 15 minute under the control of the limited flank wear.

The particles of cutting fluid are counted and sized by the aerodynamic particle sizer spectrometer as shown in Figure 1. The above data of particles of cutting fluid is recorded in the databank until the cutting time reaches 60 minutes. The maximum density of the particles of cutting fluid is set at 10 particles $/ \mathrm{cm}^{3}$, which is considered for the proper cutting condition.

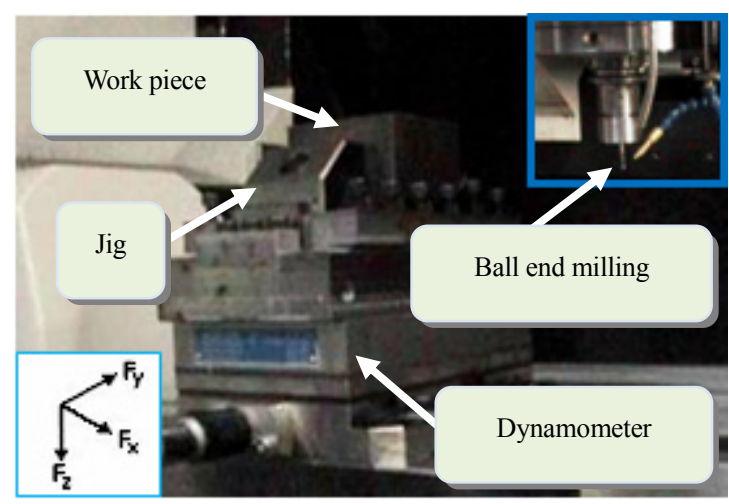

(a) A tool dynamometer

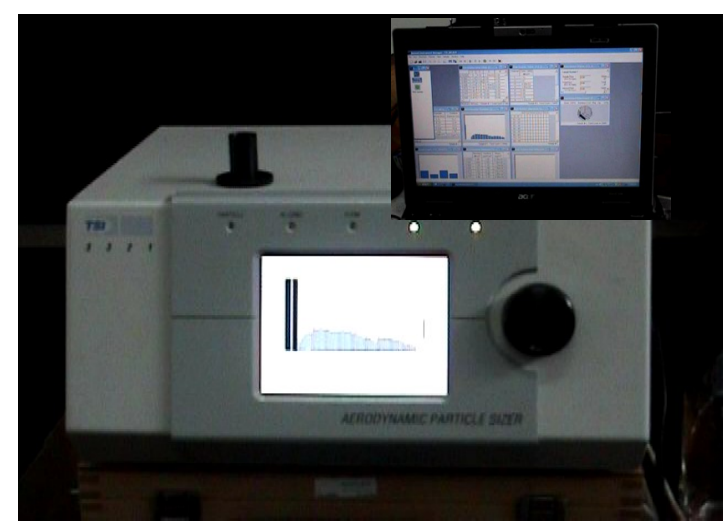

(b) An aerodynamic particle sizer spectrometer

Figure 1. Illustration of the experimental setup.

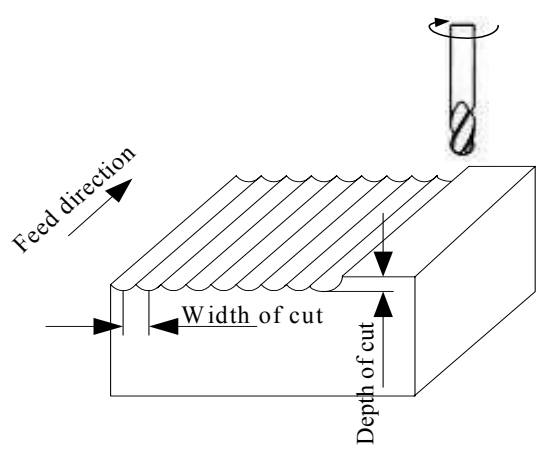

Figure 2. Illustration of the feed direction of the ball end mill. 


\section{EXPERIMENTAL RESULTS AND DISCUSSIONS}

Series of cutting tests are carried out with the different cooling strategies of the dry cutting, the wet cutting, and the mist cutting under the major cutting conditions.

All three components of cutting forces (Fx: tangential force, Fy: radial force, and Fz: axial force) are measured for the dry cutting, the wet cutting, and the mist cutting. The relation between the surface roughness and the spindle speed, and the relation between the cutting force and the spindle speed show the same trend. Some examples of experimentally obtained relation of surface roughness and spindle speed are shown in Figure 3.

Figure 3 clearly shows that the surface roughness in dry cutting is greater than the ones from the wet cutting and the mist cutting, especially at higher spindle speed. At the spindle speeds of 10,000 and 12,000 rpm, the experimentally obtained surface roughness in the dry cutting is much greater than that in the wet cutting and the mist cutting at cutting time of 30 minutes. It is understood that an increase in spindle speed causes the higher cutting temperature, which even exceeds the limit of the allowed thermal stability of the tool material (Dolinšek et al., 2001). Consequently, the tool wear rate is high, hence the surface finish of workpiece is poor.

However, the surface roughness of the spindle speed of $8,000 \mathrm{rpm}$ is lower than that of the spindle speeds of 10,000 and $12,000 \mathrm{rpm}$ in the dry cutting at the depth of cut of $0.3 \mathrm{~mm}$. It can be interpreted that the higher cutting temperature is obtained with the higher cutting speed, which cause the high tool wear rate. Consequently, the cutting force increases which affect the vibration of the cutting tool during the cutting, as a result of the poor surface finish obtained (Somkiat, 2009).

For the dry cutting, the surface roughness of the depth of cut of $0.5 \mathrm{~mm}$ is lower than that of the depth of cut of $0.3 \mathrm{~mm}$ at the spindle speed of $8,000 \mathrm{rpm}$ due to the larger cutting force. It is understood that the larger cutting area between tool edge and workpiece helps to dissipate heat which makes the dry cutting with the large depth of cut even more suitable (Somkiat, 2009).

An increase in spindle speed in the wet cutting, the surface roughness will be increased, but not in the mist cutting. It is understood that the different spindle speeds do not affect the surface roughness in the mist cutting.

Due to the effect of cutting fluid, the surface roughness in the mist cutting is lower than that in the dry cutting and the wet cutting. It is understood that the mist of cutting fluid is delivered to the inaccessible cutting area. Consequently, the cutting temperature is low, and hence the rate of tool wear is low which leads to the good surface finish as shown in Figure 4. And, the surface roughness in the mist cutting is the lowest as compared to either the wet cutting or the dry cutting at the cutting time of 60 minutes.
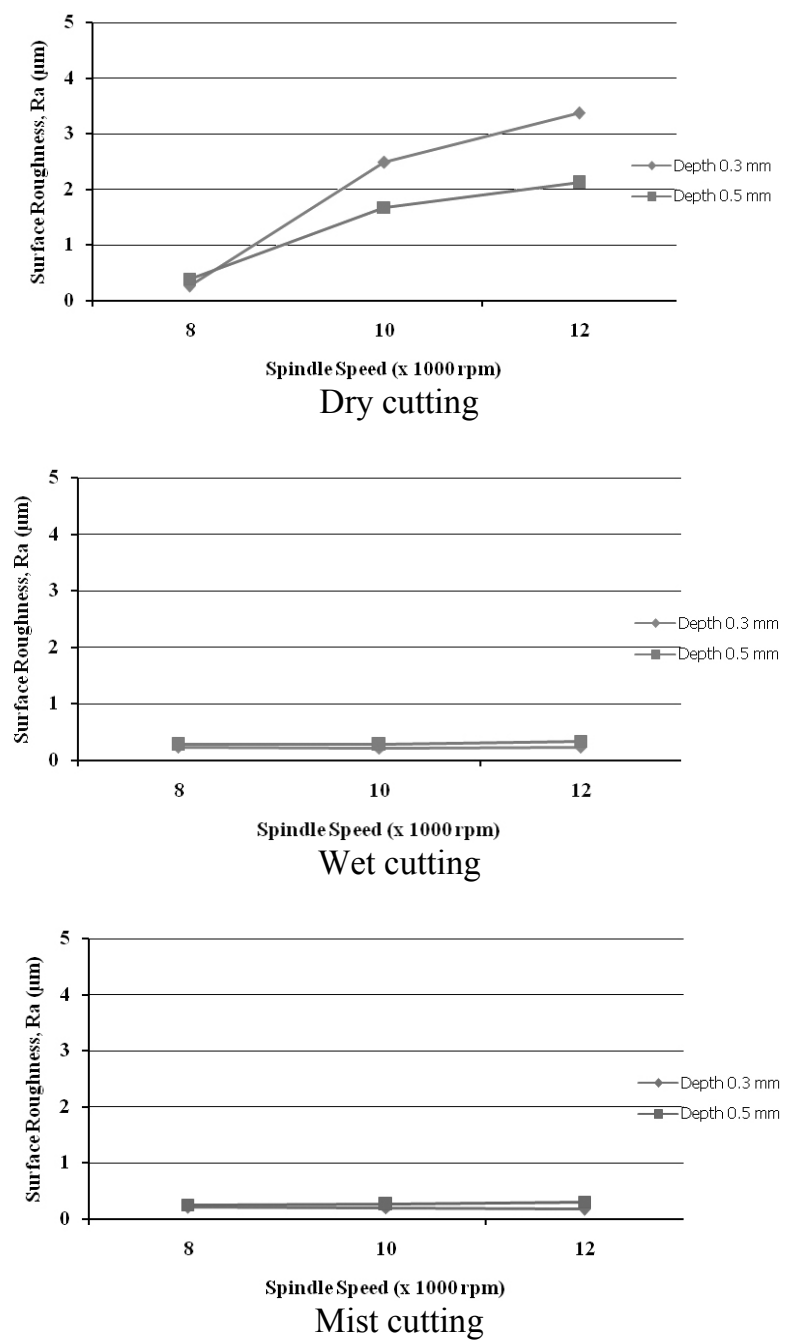

Figure 3. Illustration of the Examples of Experimentally obtained relation between spindle speed and surface roughness with dry cutting, wet cutting, and mist cutting at feed rate of $0.1 \mathrm{~mm} /$ tooth, the cutting time of 30 minutes.

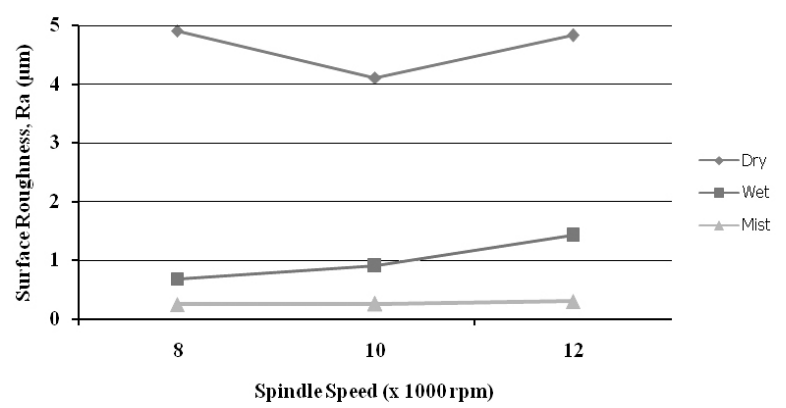

Figure 4. Illustration of the examples of experimentally obtained relation between spindle speed and surface roughness with dry cutting, wet cutting, and mist cutting at feed rate of $0.01 \mathrm{~mm} / \mathrm{tooth}$, depth of cut of $0.5 \mathrm{~mm}$, at the cutting time of $60 \mathrm{~min}-$ utes. 
While the surface roughness in the dry cutting is dropped at the spindle speed of $10,000 \mathrm{rpm}$. It is understood that the cutting temperature is suitable at this spindle speed, and then the surface roughness is lower than that of the spindle speeds of 8,000 and $12,000 \mathrm{rpm}$.

The surface roughness is the largest in the dry cutting. The main reason is that the cutting temperature is unsuitable, which causes the rapid progress of tool wear, and the higher cutting force, as a result of high surface roughness obtained.

Moreover, the quality of surface finish in ball end milling depends on the central wear (Dolinšek et al., 2001). This type of wear causes the changes in the geometrical shape of the cutting edge, consequently the wear of the cutting tool and surface roughness are increased.

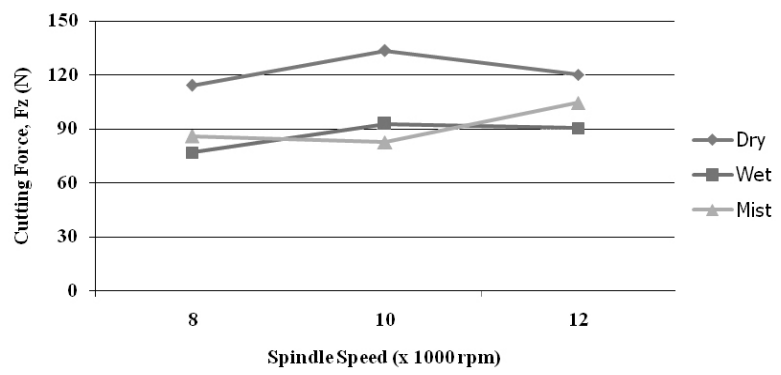

Figure 5. Illustration of the Examples of experimentally obtained relation between spindle speed and cutting force at feed rate of $0.01 \mathrm{~mm} / \mathrm{tooth}$, depth of cut of $0.3 \mathrm{~mm}$, at the cutting time of 30 minutes.

Figure 5 shows the examples of experimentally obtained relation between spindle speed and cutting force at the cutting time of 30 minutes. The in-process cutting forces are similar for all spindle speeds. For the dry cutting, the axial force $\mathrm{Fz}$ is lowest as compared to both of the wet cutting and the mist cutting. It is understood that the workpiece material becomes soft and easy to cut because of the suitable cutting temperature. While the higher axial forces are obtained from the wet cutting and the mist cutting because of the effect of the cutting fluid, which results in low cutting temperature and make workpiece material difficult to cut.

However, the axial force $\mathrm{Fz}$ for the dry cutting is the highest as compared to the wet cutting and the mist cutting as shown in Figure 6. It is understood that the contact area between tool-workpiece is large due to the larger tool wear as shown in Figure 7 and Figure 8, which affects the cutting forces.

For the mist cutting at spindle speed of $12,000 \mathrm{rpm}$, the axial force becomes larger than that of the spindle speeds of 8,000 and $10,000 \mathrm{rpm}$. This can be due to the higher heat that may burn the mist of cutting fluid before the lubrication with the higher speed as compared to the lower speed, (Tesdelen et al., 2008). Moreover, the spindle speed is high, which makes the entrance of mist of cutting fluid close to the cutting area difficult and makes the work of mist of cutting fluid more insufficient.

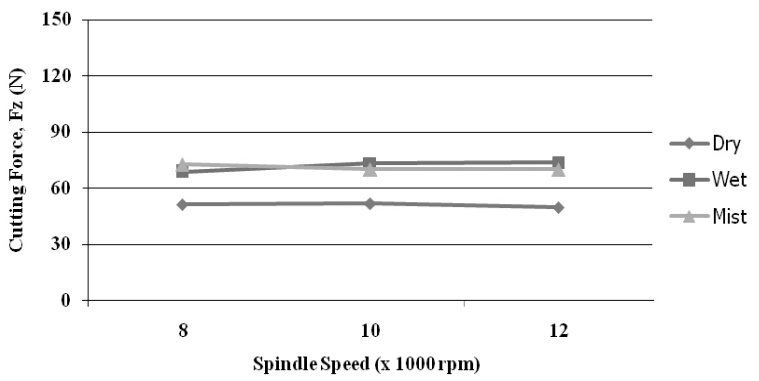

Figure 6. Examples of the experimentally obtained relation between spindle speed and cutting force at feed rate of $0.01 \mathrm{~mm} /$ tooth, depth of cut of $0.3 \mathrm{~mm}$, at the cutting time of 60 minutes.

According to Figure 5 and Figure 6, it is understood that the cutting fluid is not useful, which causes the unsuitable cutting temperature at the shorter cutting time of 30 minutes, hence the axial forces of both the wet cutting and the mist cutting are higher than that of the dry cutting. However, the cutting fluid helps to obtain the suitable cutting temperature at the longer cutting time of 60 minutes. The rates of tool wear of the wet cutting and the mist cutting are smaller than that of the dry cutting, hence the axial forces become lower.

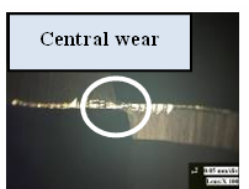

$8,000 \mathrm{rpm}$

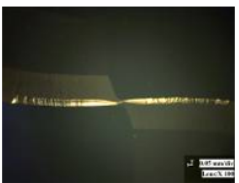

$8,000 \mathrm{rpm}$

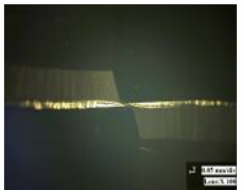

$8,000 \mathrm{rpm}$

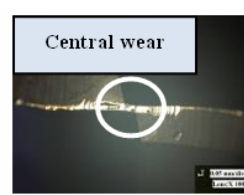

$10,000 \mathrm{rpm}$ Dry cutting

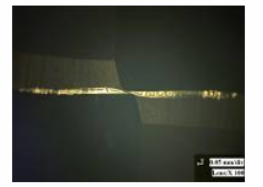

$10,000 \mathrm{rpm}$ Wet cutting

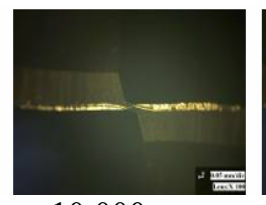

$10,000 \mathrm{rpm}$ Mist cutting

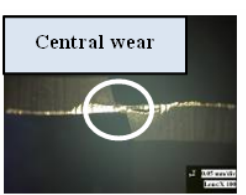

$12,000 \mathrm{rpm}$

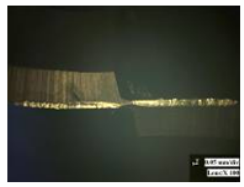

$12,000 \mathrm{rpm}$

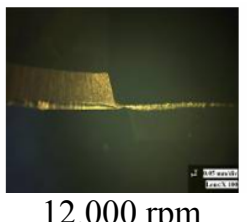

$12,000 \mathrm{rpm}$
Figure 7. Photographs of the experimentally obtained tool wear obtained from dry, wet and mist cutting with the various spindle speeds, feed rate of 0.01 $\mathrm{mm} / \mathrm{tooth}$, depth of cut of $0.3 \mathrm{~mm}$ at the cutting time of 30 minutes. 
Figure 7 and Figure 8 show the photographs of the experimentally obtained tool wear from the dry, wet, and mist cutting at the cutting times of 30 and 60 minutes, respectively. The figures clearly show that the cutting fluid can help to reduce the rate of tool wear. Since the central wear from the wet cutting and the mist cutting is smaller than that from the dry cutting. Hence, the surface roughness obtained from the dry cutting are larger as shown in Figure 4.

Figure 9 also shows the examples of the photographs of the experimentally obtained tool wear from the dry cutting at the spindle speed of $8,000 \mathrm{rpm}$, feed rate of $0.01 \mathrm{~mm} /$ tooth, depth of cut of $0.3 \mathrm{~mm}$ with the different tool diameters of 6 and $8 \mathrm{~mm}$, at the cutting times of 30 and 45 minutes, respectively. It is understood that the rate of tool wear becomes lower while cutting with the larger tool diameter. The reason is the same as mention before due to the larger cutting area between the tool edge and the workpiece which helps to dissipate the heat. Consequently, the tool wear rate decreases.

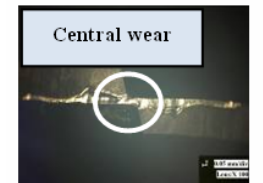

$8,000 \mathrm{rpm}$

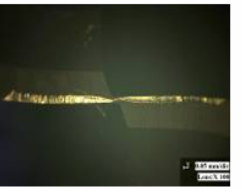

$8,000 \mathrm{rpm}$

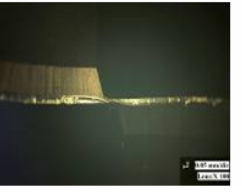

$8,000 \mathrm{rpm}$

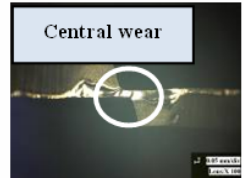

$10,000 \mathrm{rpm}$ Dry cutting

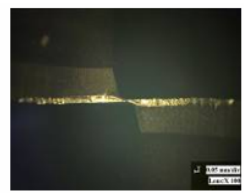

$10,000 \mathrm{rpm}$ Wet cutting

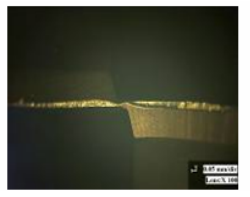

$10,000 \mathrm{rpm}$ Mist cutting

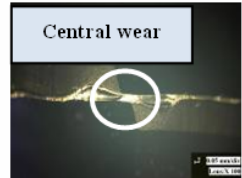

$12,000 \mathrm{rpm}$

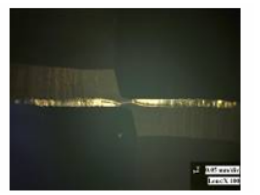

$12,000 \mathrm{rpm}$

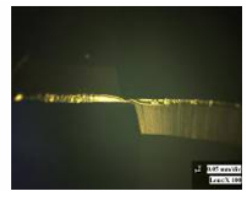

$12,000 \mathrm{rpm}$
Figure 8. Photographs of the experimentally obtained tool wear obtained from dry, wet and mist cutting with the various spindle speeds, feed rate of 0.01 $\mathrm{mm} / \mathrm{tooth}$, depth of cut of $0.3 \mathrm{~mm}$ at the cutting time of 60 minutes.

Figure 10 shows the comparison of experimentally obtained particles in working area during cutting with the wet cutting and the mist cutting at air pressure 0.5 MPa at depth of cut $0.5 \mathrm{~mm}$, feed rate $0.01 \mathrm{~mm} /$ tooth at the cutting time of 60 minutes. The aerodynamic diameter of the particles in the working area, which have the largest number of particles, is $0.5 \mu \mathrm{m}$ for all cases. But

the side scatter is low because of the small size of itself. The maximum density of particles of cutting fluids from the mist cutting is approximate 5.5 particles $/ \mathrm{cm}^{3}$.

According to the experimentally obtained results, it is understood that the in-process cutting forces obtained by employing the tool dynamometer can be used to predict the surface roughness during the in-process cutting.

In order to size and count the particles of cutting, the aerodynamic particle sizer spectrometer is put far from the machine about $150 \mathrm{~cm}$. The experimental results are obtained by time-of-flight and light-scatteringsignal techniques. Hence, the size of particles is presented by aerodynamic diameter $(\mu \mathrm{m})$ and side scatter.

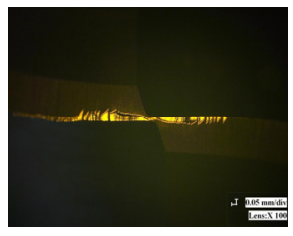

30 minutes

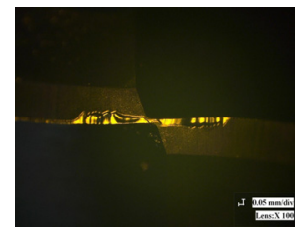

45 minutes

Tool diameter $6 \mathrm{~mm}$

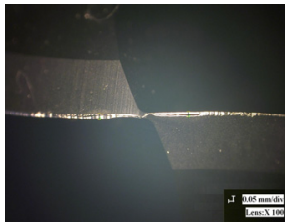

30 minutes

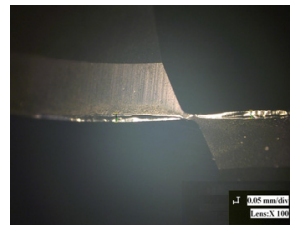

45 minutes
Tool diameter $8 \mathrm{~mm}$

Figure 9. Photographs of the experimentally obtained tool wear from dry cutting at feed rate of $0.01 \mathrm{~mm} /$ tooth, depth of cut of $0.3 \mathrm{~mm}$ with the different tool diameters at the cutting times of 30 and 45 minutes and the spindle speed of $8,000 \mathrm{rpm}$.

However, the acceptable maximum density of the particles of cutting fluid is less than 10 particles $/ \mathrm{cm}^{3}$, the mist cutting is hence considerable for the paper cutting condition.

Figure 11 shows the progress rates of the flank wear with the dry cutting, the wet cutting and the mist cutting at the spindle speed of $10,000 \mathrm{rpm}$. The experimentally obtained progress rate of flank wear is low with the mist cutting. It is understood that the cutting temperature is suitable which causes the softening material and easy to cut. While the cutting temperatures of the dry cutting is higher than the ones of the wet cutting and the mist cutting. Hence, the rate of tool wear of dry cutting is higher than the others.

The good quality of surface finish is obtained at a small feed rate of $0.01 \mathrm{~mm} /$ tooth as shown in Figure 12 . Since the surface roughness depends on the feed rate due to the theoretical surface roughness. The large feed rate gives the high feed marks left on the machined surface, hence the higher surface roughness occurs. The other reason is that the high cutting force occurs due to 
the large feed rate which affects the vibration of cutting tool during the cutting, as a consequence of the poor surface finish obtained.

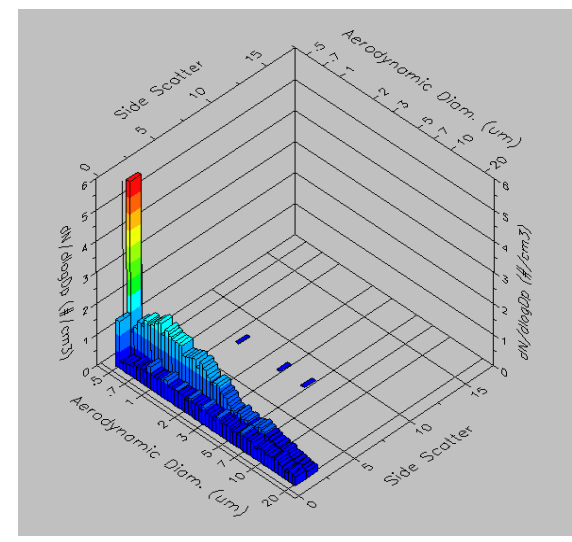

Wet cutting

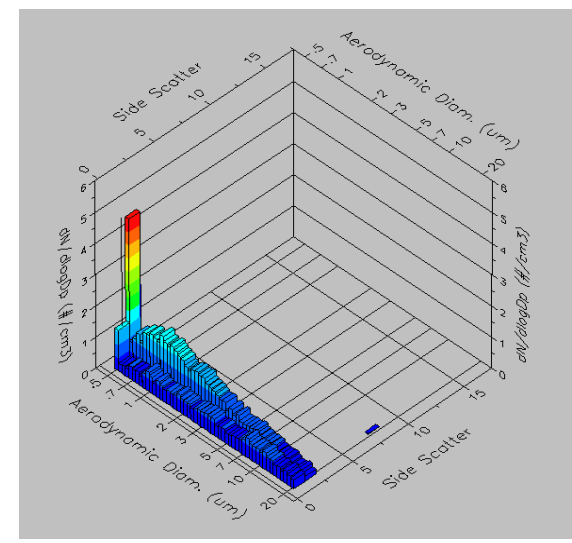

$$
\text { Mist cutting }
$$

Figure 10. Illustration of the comparison of experimentally obtained particles in working area during cutting with wet cutting and mist cutting at air pressure of $0.5 \mathrm{MPa}$ at feed rate of $0.01 \mathrm{~mm} /$ tooth, depth of cut of $0.5 \mathrm{~mm}$ at cutting time of 60 minutes.

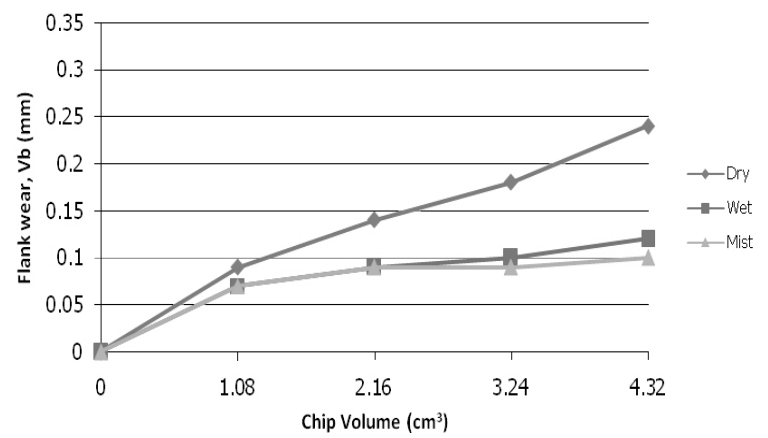

Figure 11. Illustration of the examples of experimentally obtained relation between chip volume and flank wear at the feed rate of $0.01 \mathrm{~mm} /$ tooth, depth of cut of $0.3 \mathrm{~mm}$, and the spindle speed of $10,000 \mathrm{nrpm}$.

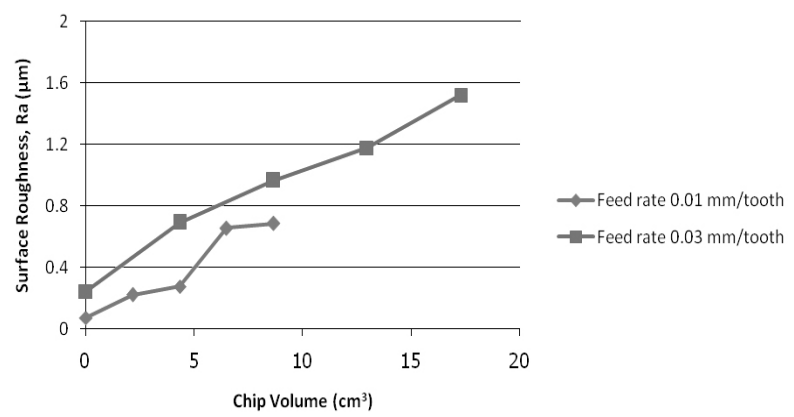

Figure 12. Illustration of the examples of experimentally obtained relation between chip volume and surface roughness in wet cutting at depth of cut of $0.5 \mathrm{~mm}$ and the spindle speed of $8,000 \mathrm{rpm}$.

\section{CUTTING COST ANALYSIS}

The cost of cutting consists of cutting tool cost and cutting fluid cost. In order to calculate the cutting tool cost, the relations of the tool wear $\left(\mathrm{V}_{\mathrm{b}}, \mathrm{mm}\right)$, the cutting time ( $T, \mathrm{~min})$, and the cutting condition such as the spindle speed ( $v, \mathrm{rpm})$, feed rate (f, $\mathrm{mm} /$ tooth), the depth of cut $(\mathrm{D}, \mathrm{mm})$ are generalized and developed by utilizing the multiple regression analysis based on the experimental data at $95 \%$ confident level.

Hence, the experimentally obtained models of the tool wear with the different cooling strategies are proposed here as:

for the wet cutting;

$$
\begin{aligned}
V_{b}= & 0.106+(-1.56 e-06) v+(-0.323) f \\
& +(-0.038) D+(0.001) T
\end{aligned}
$$

for the mist cutting;

$$
\begin{aligned}
V_{b}= & 0.143+(-3.04 e-06) v+(0.514) f \\
& +(-0.135) D+(0.001) T
\end{aligned}
$$

for the dry cutting;

$$
\begin{aligned}
V_{b}= & 0.086+(7.37 e-08) v+(-2.278) f \\
& +(-0.007) D+(0.002) T
\end{aligned}
$$

The above models show the sensitivity of the multiple regression of the flank wear to the cutting conditions and the cutting time. The coefficient of each parameter means to the responsibility of those parameters to the models, while the sign of the coefficient means to how it affects to the flank wear.

The experimentally obtained flank wear models are valid at the high significance $(\mathrm{P}$-value $=0.000)$ of $95 \%$ confident level. Therefore, the experimentally obtained models can be used to estimate the tool life in order to calculate the tool cost. Figure 13 shows the examples of the comparison of the measured flank wear and the calculated flank wear from the models. It indicates that the 
flank wear models for wet, mist and dry cutting can be effectively used to monitor and estimate the flank wear.

Since the progress of the flank wear is complicated which depends on the combinations of the cutting condition, the cutting time, the cooling strategy and the cutting temperature as mentioned before in Figures 3 to 6 . Hence, the signs and the coefficients obtained from the experimental data are different and not predictable for wet, mist and dry cutting as shown in the above models.

The proposed models are developed from the actual cutting data with no any dummy level sets, it can be effectively used to estimate the tool wear for any cutting conditions while the others cannot. It is implied that the higher cutting performance can be achieved which leads to the lower production cost by reducing the cutting fluid.

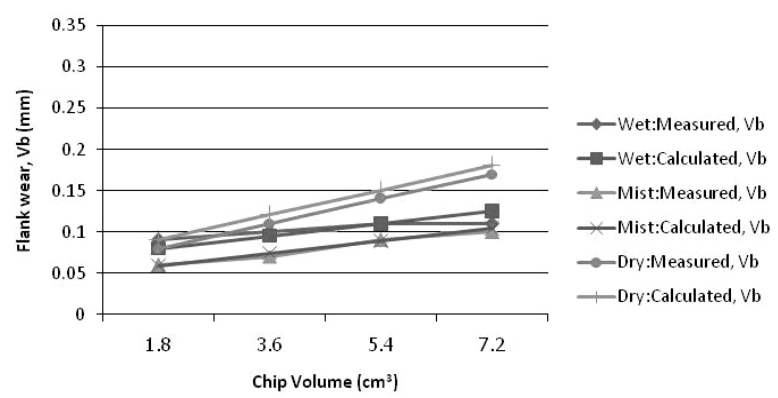

Figure 13. Illustration of the comparison measured flank wear and the calculated flank wear with the chip volume from dry, wet, and mist cutting, at the feed rate of $0.01 \mathrm{~mm} /$ tooth, depth of cut of $0.5 \mathrm{~mm}$, and spindle speed of $10,000 \mathrm{rpm}$.

The tool life is set at the flank wear of $0.2 \mathrm{~mm}$. The cost of one coated carbide ball end mill is 790 Baht. The life of cutting fluid used in the machine for wet cutting is about 1,000 hours. However, the cutting fluid applied with the mist cutting can be used for 3,806 hours with the same volume as the wet cutting. The loss rate of the mist of the cutting fluid is about $0.931 \%$. The cutting fluid costs about 266.33 Baht/liter. The consumption rate and the cost of cutting fluid used in the wet cutting and the mist cutting are calculated and shown in Table 2. It is understood that the cost of cutting fluid of the mist cutting is cheaper than the wet cutting.

Table 2. Calculation of cutting fluid cost.

\begin{tabular}{|c|c|c|}
\hline & Wet cutting & Mist cutting \\
\hline \hline $\begin{array}{c}\text { Consumption rate } \\
\text { (Liter/hour) }\end{array}$ & 0.01196 & 0.00314 \\
\hline Cost (Baht/hour) & 3.185 & 0.836 \\
\hline
\end{tabular}

Table 3 summarizes the comparison of experimentally obtained results of the tool life, the surface roughness, the density of the particles of cutting fluid, and the cost of cutting fluid under any cutting conditions for the dry cutting, the wet cutting, and the mist cutting at the cutting time of 60 minutes. The tool life can be prolonged by using the wet cutting and the mist cutting for all spindle speeds, while the surface roughness for the mist cutting is lowest for the spindle speed of 10,000 rpm. The mist cutting leads to the practice of minimum quantity lubrication (MQL) with major benefit reducing the cost of cutting fluids compared to the wet cutting, which corresponds to the Figure 13.

Referring to the criterion of the surface roughness, the longest tool life, the MQL, and the minimum cutting cost, the suitable cutting condition obtained is the mist cutting at the spindle speed of $10,000 \mathrm{rpm}$, the depth of cut of $0.5 \mathrm{~mm}$ and the feed rate of $0.01 \mathrm{~mm} /$ tooth.

\section{CONCLUSIONS}

In order to obtain the proper cutting condition, the in-process monitoring is proposed and utilized to investigate the cutting conditions with the dry cutting, the wet cutting, and the mist cutting in the ball-end milling process. The dynamometer is employed and installed on the turret of CNC turning machine in order to monitor the in-process cutting forces. The cutting forces obtained are analyzed and interpreted for the in-process

Table 3. Major cutting condition.

\begin{tabular}{|c|c|c|c|c|c|c|}
\hline \multirow{2}{*}{ Feed rate 0.01 mm/tooth } & \multicolumn{4}{|c|}{ Spindle Speed (Rev/min) } \\
\cline { 2 - 7 } & \multicolumn{2}{|c|}{8,000} & \multicolumn{2}{|c|}{10,000} & \multicolumn{2}{c|}{12,000} \\
\cline { 2 - 7 } & \multicolumn{2}{|c|}{ Depth of Cut (mm) } & \multicolumn{2}{|c|}{ Depth of Cut (mm) } & \multicolumn{2}{c|}{ Depth of Cut (mm) } \\
\cline { 2 - 7 } & 0.3 & 0.5 & 0.3 & 0.5 & 0.3 & 0.5 \\
\hline \hline Tool life (minute) & $\mathrm{D}<\mathrm{W}=\mathrm{M}$ & $\mathrm{D}<\mathrm{W}<\mathrm{M}$ & $\mathrm{D}<\mathrm{W}<\mathrm{M}$ & $\mathrm{D}<\mathrm{W}<\mathrm{M}$ & $\mathrm{D}<\mathrm{W}=\mathrm{M}$ & $\mathrm{D}=\mathrm{W}<\mathrm{M}$ \\
\hline Surface Roughness, Ra $(\mu \mathrm{m})$ & $\mathrm{D}>\mathrm{W}>\mathrm{M}$ & $\mathrm{D}>\mathrm{W}>\mathrm{M}$ & $\mathrm{D}>\mathrm{W}>\mathrm{M}$ & $\mathrm{D}>\mathrm{W}>\mathrm{M}$ & $\mathrm{D}>\mathrm{W}>\mathrm{M}$ & $\mathrm{D}>\mathrm{W}>\mathrm{M}$ \\
\hline $\begin{array}{c}\text { Density of Particles of Cutting } \\
\text { Fluids Dispersed (particles/cm }\end{array}$ & $\mathrm{W}<\mathrm{M}$ & $\mathrm{W}<\mathrm{M}$ & $\mathrm{W}<\mathrm{M}$ & $\mathrm{W}<\mathrm{M}$ & $\mathrm{W}<\mathrm{M}$ & $\mathrm{W}<\mathrm{M}$ \\
\hline Cost of Cutting Fluid (Baht/hour) & $\mathrm{W}>\mathrm{M}$ & $\mathrm{W}>\mathrm{M}$ & $\mathrm{W}>\mathrm{M}$ & $\mathrm{W}>\mathrm{M}$ & $\mathrm{W}>\mathrm{M}$ & $\mathrm{W}>\mathrm{M}$ \\
\hline
\end{tabular}


cutting temperature, the surface roughness, and the tool wear under various cutting conditions. The phenomena of the surface roughness, the cutting temperature, and the tool wear, which are dynamically changed by the cutting time, can be explained very well by the experimentally obtained in-process cutting forces.

The particles of cutting fluid dispersed in working area during the cutting is monitored by the aerodynamic particle sizer spectrometer to check the application of the wet cutting and the mist cutting for the environmentally friendly process without the environmental hazard.

Based on observations, the cutting temperature can help to cut the workpiece easier but it may sometimes give the higher rate of tool wear which depends on the cutting situations. The tool wear affects the cutting force and the surface roughness. An increase in cutting force causes the poor surface finish.

In order to calculate the cutting tool cost, the relations of the tool wear, the cutting time, and the cutting condition such as the spindle speed, feed rate, the depth of cut are generalized and developed by utilizing the multiple regression analysis based on the experimental data at $95 \%$ confident level.

The most suitable cutting condition is experimentally obtained and determined based on the criteria of the surface roughness of the machined part, the life of the cutting tool, the use of the cutting fluid, the density of the particles of cutting fluid dispersed in the working area, and the cost of the cutting fluid.

The experimentally obtained proper cutting condition is the mist cutting at spindle speed of $10,000 \mathrm{rpm}$, the depth of cut of $0.5 \mathrm{~mm}$, the feed rate of 0.01 $\mathrm{mm} /$ tooth and the maximum density of particles is about 5.5 particles $/ \mathrm{cm}^{3}$.

\section{ACKNOWLEDGMENT}

This work was supported by Office of National Research Council of Thailand, Thailand from October 2008 to September 2010.

\section{REFERENCES}

7-Leaders Corp. (2007/2008), End mills, Drills, Reamers Solid Carbide Cutting Tools Catalog, 39.

Cakir, O., Kiyak, M., and Altan, E. (2004), Comparison of gases applications to wet and dry cutting in turning, Journal of Materials Processing Technology, 153, 35-41.

Dhar, N. R., Islam, M. W., and Mithu, M. A. H. (2006), The influence of minimum quantity lubricant (MQL) on cutting temperature, chip and dimensional accuracy in turning AISI-1040 steel, Journal of Materials Processing Technology, 171, 93-99.
Diniz, A. E. and Micaroni, R. (2002), Cutting conditions for finish turning process aiming: the use of dry cutting, International Journal of Machine Tools and Manufacture, 42, 899-904.

Dolinšek S., Šuštaršic B., and Kopac J. (2001), Wear mechanisms of cutting tools in high-speed cutting processes, Wear, 250, 349-356.

Gunter, K. L. and Sutherland, J. W. (1999), An experimental investigation into the effect of process conditions on the mass concentration of cutting fluid mist in turning, Journal of Cleaner Production, 7, 341-350.

Kishawy, H. A., Dumitrescu, Ng, E. G., and Elbestawi, M. A. (2005), Effect of coolant strategy on tool performance, chip morphology and surface quality during high-speed machining of A356 aluminum alloy, International Journal of Machine Tools and Manufacture, 45, 219-227.

Ii, M., Eda, H., Imai, T., Nishimura, M., Kawasaki, T., Shimizu, J., Yamamoto T., and Zhou, L. (2000), Development of water-content cutting fluids with a new concept fire prevention and environmental protection, Journal of the International Societies for Precision Engineering and Nanotechnology, 24, 231-236.

Rahman, M., Kumar, A. S., and Salam, M. U. (2002), Experimental evaluation on the effect of minimal quantities of lubricant in milling, International Journal of Machine Tools and Manufacture, 2, 539-547.

Somkiat, T. (2009), In-process investigation of turning process applied with and without cutting fluid, $\mathrm{Jo}_{0}$ urnal of mechanical engineering, 6, 85-102.

Sutherland, J. W., Kulur, V. N., and King, N. C. (2000), An experimental investigation of air quality in wet and dry turning, Annals of the CIRP, 49, 61-64.

Thepsonthi, T., Hamdi, M., and Mitsui, K. (2009), Investigation into minimal-cutting-fluid application in high-speed milling of hardened steel using carbide mills, International Journal of Machine Tools and Manufacture, 49, 156-162.

Varadarajan, A. S., Philip, P. K., and Ramamoorthy, B. (2002), Investigations on hard turning with minimal cutting fluid application (HTMF) and its comparison with dry and wet turning, International $\mathrm{Jo}_{\mathrm{O}}$ urnal of Machine Tools and Manufacture, 42, 193200.

Weinert, K., Inasaki, I., Sutherland, J. W., and Wakabayashi, T. (2004), Dry machining and minimum quantity lubrication, Annals of the CIRP, 53, 511-537.

Tasdelen B., Thordenberg H., and Olofsson D. (2008), An experimental investigateion on contact length during minimum quantity lubrication (MQL) machining, Journal of Materials Processing Technology, 203, 221-231. 